\title{
Anesthesia management in a patient with zellweger syndrome
}

\section{Gökhan Kılınç ${ }^{1 *}$}

\section{Abstract}

Objective: Zellweger syndrome (ZS) is an autosomal recessive disorder in the spectrum of peroxisome biogenesis disorders including punctate and is defined as cerebrohepatorenal syndrome due to multiple congenital anomalies including brain, liver and kidneys. We wanted to draw attention to this issue by sharing our anesthetic experiences in a child with Zellweger syndrome.

Case: Appendectomy was planned by pediatric surgery in a 4 year old and $16 \mathrm{~kg}$ male patient who was diagnosed as Zellweger syndrome. Physical examination revealed large forehead, large tongue, small chinhypotony, mental motor retardation, and hepatosplenomegaly. Following the introduction of routine monitors, anesthesia were induced intravenously and maintained with sevoflurane in an 50\% oxygen- 50\% air mixture. The patient was intubated and ventilated with a safe pressure control mode. The patient was hemodynamically stable during surgery. After spontaneous breathing of the patient, extubation was applied smoothly.

Conclusion: Zellweger syndrome includes alarming features for the anesthesiologist. Before any procedure, the pulmonary condition should be carefully evaluated. Hepatic dysfunction may lead to a change in the metabolism of drugs based on hypoalbuminemia, coagulopathy and liver pathways. Since liver dysfunction may lead to coagulopathy, caution should be exercised when applying regional anesthesia techniques.

Keywords: Zellweger syndrome, anesthesia, appendectomy

\section{Introduction}

Zellweger syndrome (ZS), neonatal adrenoleukodystrophy (ALD), infantile refsum disease (IRD) and rhizomelic chondrodysplasia punctata (RCP) peroxisome biogenesis disorders in the spectrum of autosomal recessive disease is an autosomal recession and generalized with impairment of peroxisomal functions. This syndrome is also referred to as cerebrohepatorenal syndrome due to multiple congenital anomalies involving the brain, liver and kidneys. Facial dysmorphism, neonatal hypotonia, poor nutrition, neurocognitive delay and seizures, hepatomegaly and renal cysts are the main features of this disease. Life expectancy is approximately 6 months (1).

Peroxisomes are organelles which are found in all body cells except mature erythrocytes and especially myelin, and their main function is the biosynthesis of plasmogenic pathways in the pathway of fatty acids metabolism. Zellweger Syndrome (ZS), the prototype and the most serious of peroxisomal defects, is a very rare disease with autosomal recessive inheritance. The genetic defect in Zellweger Syndrome arises from the mutation of the PXR1 gene located on chromosome 12 and first described by Hans Zellweger (2).
We aimed to contribute to the literature by presenting the anesthesia approach during appendectomy in a 4 year old patient with ZS.

\section{Case}

Appendectomy was planned for acute appendicitis by pediatric surgery in a 4 year old and $16 \mathrm{~kg}$ male patient who was diagnosed as Zellweger syndrome. Physical examination revealed large forehead, large tongue, small chinhypotony, mental motor retardation, and hepatosplenomegaly. $\mathrm{Hb}$ : $12.1 \mathrm{gr} / \mathrm{dl}$, aspartate aminotransferase: $22 \mathrm{U} / \mathrm{l}$, alanine aminotransferase : $9 \mathrm{U} / 1$ were found in the patient who did not have any problems of bleeding clotting system. The patient was diagnosed with epilepsy and used valproic acid for treatment. The patient who had a fasting period of 6 hours before the anesthesia application was taken to the operating room.

Saturation (SpO2), heart rate $(\mathrm{CAD})$ by electrocardiography, and non-invasive blood pressure (BP) measurement was conducted. 
Following the introduction of routine monitors, a $24 \mathrm{G}$ intravenous cannula was inserted at the left brachial vein, anesthesia, midazolam $1 \mathrm{mg}$, propofol $2 \mathrm{mg} / \mathrm{kg}$ and remifentanil at $0.25 \mathrm{mcg} / \mathrm{kg} / \mathrm{min}$ and rocuronium bromide $0,5 \mathrm{mg} / \mathrm{kg}$ were induced intravenously and maintained with sevoflurane in an $50 \%$ oxygen- $50 \%$ air mixture. The patient was intubated with endotracheal tube No. 5 and ventilated with a safe pressure control mode. The patient was delivered to the surgical team and the operation started. The patient was hemodynamically stable during surgery. After spontaneous breathing of the patient, sugammadex 2 $\mathrm{mg} / \mathrm{kg}$ was administered for reversing the neuromuscular blockade at the end of the procedure and extubation was applied smoothly. The patient was sent for follow-up to the pediatric intensive care unit as planned.

Informed consent was obtained from the patient's family for being included in the study.

\section{Discussion}

ZS is a serious disease with multiple congenital anomalies which are progressive and fatal. While the affected children can live only 2-3 months, there are reports of patients living up to 2 years with more care and genetic-phenotypic variability. Patients with ZS typically die from apnea, respiratory failure or infection complications (3). Our patient was the first 4 years old patient in the literature.

Zellweger syndrome includes alarming features for the anesthesiologist. Before any procedure, the pulmonary condition should be carefully evaluated. Sedation is not recommended because it may increase the respiratory failure due to hypotonia. It is not recommended to use succinylcholine as a muscle relaxant due to the risk of possible hyperkalemia in children with ZS and nondepolarizing muscle relaxants should be used with caution because of hypotonia present in patients with ZS (4). Hepatic dysfunction in patients with Zellweger syndrome may lead to a change in the metabolism of drugs based on hypoalbuminemia, coagulopathy and liver pathways. Chronic use of anticonvulsant drugs may also alter liver function (5). Since liver dysfunction may lead to coagulopathy, caution should be exercised when applying regional anesthesia techniques. The use of anesthetic agents that reduce the seizure threshold should also be avoided. Because of the use of anticonvulsant medication due to epilepsy in our patient, liver function tests and coagulation tests were carefully examined and found to be normal.

Renal functions of these patients may also be impaired. Stress response may be insufficient in these patients, and some patients may require steroid administration in the perioperative period. Antibiotic prophylaxis is required for children with congenital heart disease. Joint contractures in patients with Zellweger syndrome may complicate venous cannulation. It may be difficult to give intraoperative position to the patients and protective pad applications may be required (6).

\section{Conclusion}

As a result, ZS is a short-lived, progressive, complex disease that affects many organs. Since children with ZS have respiratory problems, hepatic dysfunction, gastrooesophageal reflux, epileptic seizures and severe hypotonia, anesthesia planning and management should focus on these points.

Acknowledgement: During this study, no financial or spiritual support was received neither from any pharmaceutical company that has a direct connection with the research subject, nor from a company that provides or produces medical instruments and materials which may negatively affect the evaluation process of this study

Conflict of Interest: The authors declare no potential conflicts of interest with respect to the research, authorship, and/or publication of this article.

Author's Contributions: G.K, were contributed to planning the research, patient examination, preparation of the article.

Ethical issues: All Authors declare, originality and ethical approval of research. Responsibilities of research, responsibilities against local ethics commission are under the Authors responsibilities.

\section{References}

1. Bahar OC, Arun O, Simsek M, Yildirim S, Oc M, Duman A. Anesthetic management of an infant with Zellweger syndrome undergoing closure of patent ductus arteriosus and pulmonary artery banding: A case report. Cardiovascular Surgery. 2015;3(2):45-47.

2. Kuşkaya M. Zellweger sendromu: yenidoğan döneminde tanı konulan olgu sunumu. Ege Tıp Dergisi.48(3):203-207.

3. Lee PR, Raymond GV. Child neurology: Zellweger syndrome. Neurology. 2013;80(20):207-210.

4. Platis CM, Kachko L, Peled E, Katz J. Anesthesia for the child with Zellweger syndrome: a case report. Paediatric anaesthesia. 2006;16(3):361-362.

5. Patel D, Sharma K, Chauhan CS. Zellweger syndrome-A Short Review on Peroxisome Biogenesis Disorders (PBD).IJARPB:2014; 4(1),1-6

6. Işıı B, Arpacı H, Karaca G, Kurtipek Ö. Zellweger sendromu ön tanılı hastada manyetik rezonans görüntüleme sırasında anestezik yaklaşım. Marmara Medical Journal. 2008;21(1):73-75. 